\title{
ATUALIZAÇÃO DA SISTEMÁTICA E DA DISTRIBUIÇÃO GEOGRÁFICA DE PLANORBIDEOS NO ESTADO DO PARANÁ, BRASIL.
}

ENNIO LUZ'; SEBASTIÃO MARTINS SILVA ${ }^{2}$; ANTÔNIO PLÁCIDO DE CARVALHO ${ }^{2}$; NELSON CASTRO ${ }^{2}$

${ }^{1}$ Departamento de Patologia Básica, Setor de Ciências Biológicas -Universidade Federal do Paraná.

${ }^{2}$ Fundação Nacional de Saúde, Paraná.

Os autores fazem uma atualização da distribuição dos Planorbideos que ocorrem no Estado do Paraná, discutindo as classificações de autores anteriores com relação às designações genérica e específica. Encontram 9 espécies, sendo 7 Biomphalaria, 2 de Drepanotrema e uma de Antilorbis: Biomphalaria glabrata, (53 municípios) B. intermedia (6 mun.) B. occidentalis (31 mun.) B. oligoza (3 mun.) B. peregrina (81 mun.) B. straminea (22 mun.) B. tenagophila (40 mun.) Drepanotrema cimex (51 mun.) D. lucidum (10 mun.) e Antilorbis nordestensis. (17 mun.). 